Please do not remove this page

RMIT

UNIVERSITY

\title{
Why do families relinquish care? An investigation of the factors that lead to relinquishment into out-of-home respite care
}

Nankervis, K; Rosewarne, Andrea; Vassos, Maria

https://researchrepository.rmit.edu.au/esploro/outputs/9921857988101341/filesAndLinks?institution=61RMIT_INST\&index=null

Nankervis, K., Rosewarne, A., \& Vassos, M. (2011). Why do families relinquish care? An investigation of the factors that lead to relinquishment into out-of-home respite care. Journal of Intellectual Disability Research, 55(4), 422-433. https://doi.org/10.1111/j.1365-2788.2011.01389.x

Published Version: https://doi.org/10.1111/j.1365-2788.2011.01389.x

Repository homepage: https://researchrepository.rmit.edu.au

(c) 2011 The Authors. Journal of Intellectual Disability Research (c) 2011 Blackwell Publishing Ltd

Downloaded On 2023/04/26 20:22:03 +1000 
Thank you for downloading this document from the RMIT Research Repository.

The RMIT Research Repository is an open access database showcasing the research outputs of RMIT University researchers.

RMIT Research Repository: http://researchbank.rmit.edu.au/

\section{Citation:}

Nankervis, K, Rosewarne, A and Vassos, M 2011, 'Why do families relinquish care? An investigation of the factors that lead to relinquishment into out-of-home respite care', Journal of Intellectual Disability Research, vol. 55, no. 4, pp. 422-433.

See this record in the RMIT Research Repository at:

http://researchbank.rmit.edu.au/view/rmit:11603

Version: Accepted Manuscript

Copyright Statement: (c) 2011 The Authors. Journal of Intellectual Disability Research (C) 2011 Blackwell Publishing Ltd

Link to Published Version:

http://researchbank.rmit.edu.au/view/rmit:11603

\section{PLEASE DO NOT REMOVE THIS PAGE}


Running Head: FACTORS LEADING TO RELINQUISHMENT

Why do families relinquish care? An investigation of the factors that lead to relinquishment into outof-home respite care

Nankervis, K. L., Rosewarne, A. C., \& Vassos, M. V. 


\section{Abstract}

Background: Families/carers relinquishing the care of family members with a disability into the care of out-of-home respite facilities is an under researched area in the disability field. With this in mind, the aim of this study was to explore the factors that lead to families relinquishing care, the potential early indicators that families are considering relinquishment; the factors that may prevent relinquishment and the outcomes for families/carers after relinquishment occurs. Method: Thirty two client files (of individuals for whom families have relinquished their care in a defined 12 month period) were reviewed for information around their relinquishment into out-of-home respite care facilities for an extended stay. Staff members involved with these families (a total of 17) were also interviewed to provide more information. Results: A thematic analysis of the results found that the factors that led to relinquishment could be categorised into; (a) characteristics inherent to the individual with intellectual disability; (b) characteristics inherent to the family/carer; and (c) characteristics associated with the support context that the carer/family is currently experiencing. It was also found that families/carers' experienced positive outcomes after relinquishment had occurred however feelings of guilt and mourning were initially felt. Conclusions: Extra supports (e.g., increased respite care, planning for movement of the family member into out-of-home permanent accommodation, and case management) and positive interventions such as parent training were highlighted as potential strategies to achieve more lasting benefits from short-stay out-of-home respite care.

Keywords: Relinquishment, intellectual disability, families, quality of life, respite. 
Why do families relinquish care? An investigation into the factors that lead to relinquishment into out-of-home respite care facilities

Caring for individuals with intellectual disability is both a positive and challenging experience for families. While there are studies that highlight the positives for families associated with the caring role, e.g., Grant et al. (1998) who found that gratification from caring is gained from seeing that their relative is well cared for and is developing new skills, a larger amount of studies highlight the psychological and quality of life impact that caring has on families. In a review by Cummins (2001), studies indicated that higher than normal levels of stress, depression and anxiety are reported in carers of people with disabilities as are financial problems, reduced access to social activities and low levels of informal social support. A recent study by Burton-Smith et al (2009) found similar trends for Australian carers also. Research also indicates that challenging behaviour (e.g., Hastings 2002, Bromley et al. 2004) and unmet service needs (Hare et al. 2004) are some of the common determinants of poor psychological outcomes for carers.

One service that is available to carers is respite care; when a person is placed in respite care, the individual with a disability is supported in either an out-of-home respite facility or in their own home for a short designated period of time by individuals other than the family of the individual (McNally et al. 1999). The primary purpose of respite care is to provide the usual carer with a break from their caring role (McNally et al.), hence providing carers with a chance to re-energise in order to continue to provide care. Respite care can also provide benefits to the individual who is the focus of care via social interaction with peers, a change of environment, and a break from their usual routine (McConkey et al. 2004).

The reported benefits of respite care for family carers can be summarised as: (a) having a greater sense of control; (b) improved family functioning; (c) a reduction in carer stress and depression; (d) feeling refreshed after having the opportunity to sleep, recoup and have time for themselves; (e) increased sense of normal life; (f) increased time to spend with other family members; and (g) increased chance for social outings (see Chan \& Sigafoos 2001a; Chan \& Sigafoos 2001b; Chou et al. 2008; Damiani et al. 2004; MacDonald \& Callery, 2003; McConkey et al. 2004). Respite care is in high demand for some family carers, however not all families wish to use such a service. For those families who need or use respite care, previous published studies 
have identified common characteristics that are linked with greater need for respite. These characteristics are either intrinsic to the individual who is the focus of care or their family. These characteristics are summarised in Table 1.

Insert Table 1

With the shift away from institutionalisation, trends in living arrangements have seen a reduction in the number of people living in out-of-home permanent accommodation and an increase in the number living with their family (Australian Institute of Health and Welfare; AIWH 2008a). In Australia, this trend has been largest for people with severe and profound limitations (AIHW 2008a). Accordingly, the eligibility criteria and scope of respite care services available have been expanded to support the diverse needs of a broader range of families (Freedman et al. 1999). These trends have increased the demand for respite care, with a documented significant unmet need (Chan, 2008). This unmet need is particularly apparent for people with an intellectual disability as, in Australia, people with intellectual disability account for the majority of people with disabilities who have unmet need for out-of-home permanent accommodation and respite care services (Australian Institute of Health and Welfare; AIWH 2008b).

While there are few studies reporting on the effects of unmet need for respite care, it is presumed that families not having the amount and/or type of respite care needed or desired will lead to an inability to gain the benefits afforded, namely, relief of carer stress and support to continue the caring role. In turn, it is probable that unavailable respite care will result in an escalation of the number of people being relinquished into out-of home respite care.

Relinquishment refers to families giving up the caring role of their family member with a disability. This usually leads to the family member with a disability being placed in an out-of-home respite facility until permanent accommodation can be arranged for that person (either with the family again, in out-of-home permanent accommodation or a foster family). As such, relinquishment can lead to unavailable slots in out-of-home respite facilities meaning that out-of-home respite care may not be accessible to other families. Thus leads to an exacerbation of the effects of unmet respite needs for these families. It is important to note here that 'relinquishment of care' is different from the notion of 'moving out of home'; relinquishment is instigated by families (as moving out of home is on some occasions) however relinquishment leads to an unstable situation for the 
individual who has been relinquished as permanent out-of-home accommodation has not be organised for these individuals. Therefore, they need to be placed in out-of-home respite facilities until permanent accommodation is arranged. Those who move out of home have accommodation organised prior to the move.

So what leads to a family or carer relinquishing care of their family member with an intellectual disability? The answer to this question can provide some insight into the strategies that can be put into place to improve supports for families. In terms of relinquishment into disability services, the literature is limited. However information from other related disciplines, such as the mental health literature, provides some insight into what factors could be predictive of relinquishment. Power (2008) identified; service availability, gaps in service provision, and service co-ordination as being some of the key factors that influenced parents in their decision making about relinquishing care of their mentally ill family member. Power also identified financial issues as a factor that may lead to relinquishment. These identified factors could potentially extrapolate to reasons for relinquishment in the disability sector. For example, caring for a child with a disability can restrict at least one parent from working at all or working on a full time basis hence limiting financial resources. As a result, families may find it difficult to pay for equipment and services that their child requires (Clark \& MacArthur 2008) resulting in increased stress for the carers.

If relinquishment is likely to put pressure on already highly stretched and under funded respite services, it is crucial that services are able to identify families at risk of relinquishing care in order to implement strategies to meet their needs. The aim of the present study was to investigate the relinquishment of individuals with intellectual disability into out-of-home respite care, with a focus on what factors lead to relinquishment, what were the potential risk factors for relinquishment, the potential strategies that could be implemented to improve supports for families and what were the outcomes for the family after relinquishment had occurred. This study was based on case file reviews of a sample of individuals with a disability who had been relinquished in a specified 12 month period and interviews with staff involved in the cases. Due to the sensitive nature of contacting families who had relinquished care, it was decided to not include families in this study, however it is acknowledged that information gathered directly from families is critical and should be investigated where possible in future research into this issue. 
Due to limited disability specific research with regards to relinquishment, hypothesising possible trends is difficult. For this reason, this study was exploratory allowing the reasons for, and outcomes of relinquishment to be investigated without strict parameters in place (such as independent and dependent variables). However, it was expected that some of the factors that lead to families relinquishing their family member with a disability would be consistent with those found by Power (2008) and the factors that have been found to be associated with need for respite (summarised in Table 1). This was expected because intuitively, factors that are associated with increased need for respite care may also act as the reasons why a family may relinquish if support for their caring role is not adequate.

\section{Method}

\section{Participants}

The case files for 32 individuals across four government regions of one state in Australia were reviewed. There was a marked gender imbalance in the sample, with 25 of the 32 individuals sampled being males ( 7 females). Of the regions sampled, two of the regions were metropolitan and two were rural hence allowing a representative sample of the population of the state to be sampled. The case files reviewed were of all the individuals in these regions who were relinquished in the 12 months up to the commencement of the study in March 2009. A total of 12,710 individuals use respite services in these four regions meaning that less than one percent of the population accessing respite services was relinquished into respite care. ${ }^{1}$ At the time of the study, 11 of the 32 individuals sampled were still living in a centre-based respite facility, with 8 of the 11 occupying unavailable beds (defined as respite beds that continue to be occupied after the planned period of respite has passed and no extension of the period has been granted). The other 21 individuals sampled had been moved from a centre-based respite facility into permanent accommodation (i.e., a group home). No data was available with regards to the length of time spent by each individual living in a respite facility before being moved to a group home. A further four case files of individuals who had transitioned from the family home into out-of-home permanent accommodation

\footnotetext{
${ }^{1}$ This information was provided directly to the research team. The figure of 12,710 may be an overestimation; this figure was calculated from tables indicating how many individuals use each respite service provided by each of the four regions however these figures do not take into account that individuals may use multiple services.
} 
without the family relinquishing care were reviewed however the information from these cases was not relevant to the present study.

Seventeen staff members were interviewed for this study; the primary aim of conducting the staff member interviews was to check the accuracy of the information contained in the case files and to elaborate more on some of the information contained in the case files. Given that information contained in case files may be limited or inaccurate, gaining information from two sources allows information to be triangulated hence increasing accuracy. The staff members interviewed were involved currently or had been involved in the supporting the families and individuals included in the study. Staff members included managers of accommodation, respite care, and community access services; team leaders, and case managers. In many cases, one staff member was able to provide information for a number of cases. The inclusion criteria stated previously that the individual had to be relinquished within 12 months of the study's commencement was set to aid staff with recall of information about these individuals. The study was approved by the RMIT University Human Research Ethics Committee.

The mean age of the sample (at the time of the study) was 21.59 years $(S D=11.05)$ with the males being younger $(M=21.04$ years, $S D=11.46$ years $)$ when compared to the females $(M=$ 23.57 years, $S D=9.98$ years). All of the cases involved individuals who had an intellectual disability, most commonly in conjunction with autism (37.5\%). A small percentage had intellectual disability only (15.6\%), with the rest having intellectual disability and one or more co-existing disabilities, such as physical or sensory impairments. The majority of clients came from a two parent family (64.5\%), with $19.4 \%$ coming from a single parent family, $6.5 \%$ coming from separated/divorced family and 9.7\% classified as 'other'. Most came from an Anglo Australian background with only $25.8 \%$ coming from an Aboriginal or Torres Strait Islands (ATSI) or culturally and linguistically diverse (CALD) culture.

According to the files, the majority of individuals were classified as having severe or profound disabilities (75\%) (mild or moderate disabilities: $25 \%$ ) and severe or profound levels of support needs (78.1\%) (mild or moderate support needs: $21.9 \%)$. The majority of the cases reviewed involved individuals who were reported to exhibit challenging behaviours (64.5\%), with a further $9.7 \%$ displaying challenging behaviour in combination with high medical needs. A small 
percentage had high medical needs without challenging behaviour (12.9\%) and $12.9 \%$ displayed no challenging behaviour or high medical needs. In terms of respite care use, there was an overall trend of increased requests for and increased use of respite care by the families prior to the family members with a disability being relinquished. Multiple respite care agencies (government and nongovernment) providing different forms of respite care (in-home or out-of-home respite care) were utilised by the families however out-of-home respite care was preferred by these families.

\section{Materials}

A semi-structured interview schedule was used when conducting the interviews with the staff. The interview schedule included questions about the relinquishment of the individuals, the factors that contributed to the relinquishment, and strategies that were used or could have been used to avoid the need for relinquishment. A file collection form was developed to guide the case file reviews. Demographic information such as gender and family status was collected along with information regarding the disability type and level of support needs (including challenging behaviour and medical needs). The history and nature of respite care use was recorded in detail and information regarding relinquishment was also recorded. These files contained detailed case notes from interviews, phone calls and home visits as well as assessment and other reports.

\section{Procedure and Analysis}

Government regional directors were briefed about the research project prior to the arrival of the research team. Regional directors provided the research team with access to the files of individuals in accordance with the inclusion criteria. One member of the research team reviewed each case file; no cross checking of the information extracted from each file was undertaken. After the file review was completed, staff members associated with each case were invited to be interviewed. These interviews gathered further information regarding the circumstances of relinquishment as well as respite care and other supports provided to the family. All data collected from the case files and the interviews was entered into a spreadsheet to aid analysis of the data.

Interview notes and qualitative data collected from the case files were analysed using a thematic analysis approach. This approach allows the themes present in the collected data to be identified. A theme 'represents some level of patterned response or meaning within the data set' (Braun \& Clarke 2006, p. 82). Themes were uncovered by initially coding interesting features 
embedded in the data (in a systematic fashion), collating data for each code, and then organising the codes into potential themes.

Results

Factors that Contributed to Relinquishment into Out-of-Home Respite Care

The results of the study identify multiple factors that appeared to be associated with relinquishment into out-of-home respite care. The factors can be grouped into three area: (1) characteristics associated with the individual with the disability; (2) characteristics associated with the family providing care; and, (3) characteristics associated with the nature and level of support received. These factors are summarised in Table 2 and the following subsections describe these in more detail. Non-identifying examples of actual cases reviewed are reported here (and throughout the Results section) as a means of illustrating further the themes extracted from the thematic analysis.

Insert Table 2

\section{Characteristics Associated with the Individual}

A large proportion (22 out of 32) of the files examined were of individuals who had high support needs due to high levels of challenging behaviour (e.g. hyperactivity, aggression, selfinjurious behaviours, absconding). A significant feature of these cases was: (1) the need for constant vigilance; (2) behaviours growing worse as the individual grew older; (3) carer inability to manage behaviour as the individual became physically bigger and stronger; and, (4) extreme risk of harm (i.e., to the carer and/or other siblings). Another theme extracted from the case file reviews was that individuals with high support needs because of profound or severe disability also exhibited high medical needs. Limited communication was another characteristic that appeared to be linked to relinquishment of care into out-of-home respite care. Only a small number of individuals' exhibited this however carers reported to staff that this was a significant issue for them; parents reported that they could not develop rapport with the individual and/or became disappointed when they started to realise that the individual would achieve little development.

\section{Case Example 1: A}

A was being raised by a single mother and had other siblings. A had a range of severe challenging behaviours including; violence, self injurious behaviours, property destruction, stripping in public, absconding, pica, and incontinence. The mother reported to staff that she 
had serious concerns for the safety of A's siblings. After an episode of severe behaviours, the mother telephoned the case manager saying she was 'breaking down' and could not, and would not care for A any longer.

One common theme reported in the case files and by staff across all individuals exhibiting high support needs was the issue of sleep disturbance. Many of the cases with intellectual disability had disturbed sleep patterns and those with high physical needs often required constant attention for medical needs. Carers reported to staff that these sleep patterns disrupted the sleep of all members of the family (with the mothers most effected) due to the need for constant vigilance for the safely of the individual and others. Lack of sleep was reported to staff as being a contributing factor to carer exhaustion and inability to continue providing care.

\section{Case Example 2: $B$}

B sleeps on average two hours per night. The family, including other siblings, reported to staff that they were in crisis over an extended period of time as the parents were both exhausted. B's mother collapsed from exhaustion and stress on several occasions, resulting in hospital admissions. It was after the last of these admissions that the family alerted the day placement that $B$ would not be picked up and that alternative arrangements would need to be made.

\section{Case Example 3: C}

The family of C reported to staff that they were exhausted from dealing with the C's behaviours, and trying to keep the siblings safe. $\mathrm{C}$ had a history of serious challenging behaviours including the use of weapons, extreme physical violence towards others, and property destruction. The family reported to staff that they were chronically sleep deprived due to being too afraid to sleep, with C's sibling describing himself as 'terrified' to go to sleep.

\section{Characteristics Associated with the Family}

The emotional state of the primary carer (usually the mother) was a common theme extracted from the case files and interviews with staff. Mothers were reported by staff to be experiencing depression, exhaustion, and stress mainly because the care-giving role fell primarily on to them (and not only for the family member with a disability but for significant others like aging parents). The mothers of the family members with high support needs also reported to staff feelings of isolation and receiving no support from within their families.

Staff also noted that carers expressed concerns about the effects that the family member with a disability had on the wellbeing of their siblings. Some parents reported to staff that due to 
their increased care giving role for the individual, they could not support their other children to the extent that they wanted to. Staff reported that this appeared to become more of an issue for carers when the siblings reached the latter stages of their schooling as they were concerned that their care-giving responsibilities would interfere with the academic success of the siblings.

The nature of the relationship between the parents in some instances was the main contributor to relinquishment. Staff reported that the care-giving role was harder to continue for some families due to the acrimonious relationships between parents who had divorced or separated. In one case, relinquishment was insisted by one parent who wanted to leave the marriage but did not want to leave the primary care-giver alone in the caring role. In cases such as these, the family breakdown was regarded as the major contributor to relinquishment into out-ofhome respite care by staff, not the characteristics inherent to the individual with a disability.

Relinquishment in some cases was possibly associated with parental expectations that their family member with a disability had the same right as their siblings to transition into out-ofhome permanent accommodation living when they reached adulthood. Staff reported that families began to realise that it was likely that they would have this caring role for the rest of their lives when the individual reached the age of 10-15 years. Many carers expressed a strong desire for a "normal" life to staff; and for some families, this desire was the driving force behind repeated warnings to case managers that they would relinquish once the child completed their schooling. This desire for transition from living with the family to out-of home permanent accommodation does not appear to be associated with level of support need.

For some individuals, relinquishment was reported to be due to the family carer becoming suddenly unavailable due to the frailty associated with ageing, ill health, or death. However, it should be noted that this was associated with individuals who were older in age (above 18 years).

\section{The Support Context as a Factor in Relinquishment}

Investigating the context of the supports needed and/or available to the families in these cases was important as it allowed support to be explored as a possible factor leading to relinquishment of care into out-of-home respite care. A consistent feature of the families and carers of relinquished individuals with high support needs was a reported lack of informal supports and feelings of social isolation by families to staff. Staff expressed that this left the carer or family reliant 
on a range of formal supports from a range of providers, with case files documenting that families in very difficult circumstances were provided with a large amount of and a wide range of supports. These families could be regarded as high service users, however most of these families reported to staff frustration with their service allocation because they felt that they did not have enough service allocated to them, nor the right type of service to meet their needs.

In some cases reviewed (especially situations where the carer was so highly stressed and exhausted that they could not or did not want to continue in the carer role), staff noted that some of the parents were of the view that any option provided to them would not be acceptable as the only option desired was out-of-home permanent accommodation. In these cases, the case managers reported in their case notes that no amount of service allocation would have prevented relinquishment. However, for some families, staff commented that providing more respite care (if it were available) would have assisted the family to continue to provide care and most likely would have delayed or even prevented relinquishment.

It was also reported by staff that some families were aware that relinquishing care was a potential strategy in gaining access to out-of-home permanent accommodation when this service option was not one that was readily available to them (due to significant unmet need for this type of accommodation). Some staff reported that to their knowledge, there was more than one instance where this strategy was shared between groups of parents.

Gaining access to the appropriate services that met the family's need was a recurrent theme in the cases reviewed. Staff reported many inadequacies in the system that led to their inability to coordinate appropriate supports. The possible factors extracted from the case files and interviews with staff that are believed to be affecting access to adequate supports can be grouped according to availability of respite care and availability of appropriate supports. Table 3 describes these in more detail.

Insert Table 3

What could have been done to prevent relinquishment?

The interviews with staff identified the need for strategies and interventions that directly address the factors predisposing a family to relinquishment and where appropriate, increasing the families' ability to continue caring for the individual. Several positive strategies that were suggested 
by staff included; (a) teaching parents strategies while the individual is young in order to prevent the development of challenging behaviours; (b) arranging marriage/relationship counselling before the relationship is in crisis; and, (c) treatment for carer depression.

Other strategies pinpointed as possible ways to prevent relinquishment were to provide; more out-of-home respite supports to families at critical times for the family, on-going case management support, and more shared care. The staff also emphasised the need to focus on and address the needs of the siblings as a way of preventing relinquishment. However, staff acknowledged that once a decision to relinquish care had been reached by the family, no amount of service allocation or support was likely to change the family's decision or influence the circumstances contributing to the decision to relinquish. Planned transition into out-of-home permanent accommodation at early adulthood, rather than when carers are too old to continue was acknowledged by staff as being a preventative strategy; if the family does not have this option available to them, then there can be the temptation to relinquish care to achieve it. Even so, some staff found that explicit messages to the parents that relinquishment was not a strategy to gain outof-home permanent accommodation was successful. Staff also reported that planned respite care was critical in assisting families to continue providing care. In some cases reviewed, the trigger for relinquishment was the cancellation of planned respite care the parents were relying on.

\section{Could the relinquishment have been foreseen?}

Excluding the families where the carer became suddenly unavailable due to the frailty associated with ageing, ill health, or death; there was a consistent pattern from families of escalating respite care use and requests for more respite care prior to relinquishment. Families had been stating for a considerable period of time to staff before relinquishment that they could no longer cope and that they would relinquish care. In a number of cases, these statements from the families had been documented in the case files for a number of years prior to relinquishment. However, many staff reported that they were surprised when relinquishment occurred even though the parent had been stating for some time that they could not cope. This may be due to a large number of families receiving case management services expressing an inability to cope yet continuing to care, indicating difficulty in predicting which families will actually take the step to relinquish care. 


\section{Case Example 4: D}

Six years prior to relinquishment, the mother of $D$, who has high support needs due to challenging behaviour requested out-of home permanent accommodation as she had reached the level where she could no longer tolerate her situation and she was concerned about the impact $D$ was having on her other child. At this time, the mother stated to staff that she had been considering this for some time as D's behaviour was worsening with age. Two months prior to relinquishment, the mother reported to staff that she was "at the end of the road", extremely stressed and unable to cope. D's behaviour continued to worsen. At the time of relinquishment, the mother stated to staff that the decision had been made to not take D home from the out-of-home respite facility due to fears for her own and other child's safety. Other supports were suggested by the staff but were refused by the mother as she felt that they would not be of benefit to her family and that it had taken her a long time to reach this decision.

\section{The outcomes of relinquishment}

Overall, the reported outcome of relinquishment for the family and carer (as reported by staff in the case files) was positive. Staff reported that initially, for many families (especially the mothers), there was a period of mourning and a feeling that they had 'failed' in their parenting role. Carers indicated distress to staff at having to take the drastic action of relinquishment but realised that they were not able to continue as full-time carers therefore relinquishment was a last resort. Some families reported to staff feelings of unfair judgement by others (families and service providers) for relinquishing care. Staff also reported that guilt was a major emotion experienced for having relinquished their family member into out-of-home respite care as well as feeling responsible for blocking a slot in an out-of-home respite facility (which would have an impact on other families). Staff reported that some families found their guilt overwhelming to the point of requiring counselling.

However, after time, staff reported a dramatic improvement in the family's quality of life. Staff indicated that many families reported experiencing uninterrupted sleep for the first time in years; and, feeling more relaxed and in control of their lives. Also, in the instances where marriages/relationships had been under pressure, many of them recovered - although some relationships were beyond repair. However, even in these cases, the parents/carers were able to move on with their lives and focus on their other children. Staff also noted that families reported that the siblings were happier and more settled because the family was able to concentrate on 
issues of importance to the other children; this included activities such as enjoying a meal out together, a family holiday (which was a first for some families), or supporting the study needs of a sibling. Minimal information was available with regards to the individual relinquished and their quality of life in their new care arrangements however some of the case files reported that their quality of life had improved. In almost all cases reviewed, it was reported that the family continued to have a high degree of involvement in the life of the family member relinquished into out-of-home respite care - they just did not provide care for them on a day-to-day basis. For some cases, staff noted that fathers become more involved after relinquishment compared to when the family member was living with the family.

\section{Discussion}

In summary, this study found that the factors that can lead to families and carers deciding to relinquish care can be categorised into characteristics inherent to the client (high support needs, high medical needs, limited communication and young adult age), characteristics inherent to the family (psychological distress, single parent family, parental expectations, marital breakdown, desire to have "normal" life), and characteristics associated with the support context (availability of respite care services, availability of appropriate supports; relinquishment being used as a strategy to gain out-of-home permanent accommodation). These factors were consistent with the expectation that the factors associated with increased need for respite care were also contributors to why a family relinquishes the caring role, e.g., distress, limited communication, lack of supports, and sole parenting. These are also consistent with the factors identified by Power (2008) and the literature reported in the Introduction around the psychological impact of caring (Cummins 2001; Hastings 2002; Bromley et al. 2004; Hare et al. 2004; Burton et al. 2009). Also, many of the themes uncovered around the outcomes for the family after relinquishing care indicated improved quality of life for the family - such as improved sleep and family functioning, after initial feelings of guilt, mourning and failure. Results also uncovered several themes around what services could prevent relinquishment into out-of-home respite care from occurring at all; staff highlighted that positive interventions (such as parent training, counselling and psychological intervention) need to be provided when early warning signs for relinquishment are apparent. 
When viewing the results of the study as a whole, a major theme that becomes clear is that strategies to improve supports available to families need to address the care needs of the individuals being supported as well as the carers' ability to cope with the caring role. Staff members participating in this study reflected on possible interventions that could be used to enhance the carer's ability to cope (e.g., interventions to decrease challenging behaviours and increase skills in daily living, parent training, linkage with informal supports) however these strategies did not appear to be utilised by services as a means to prevent relinquishment in the cases reviewed; offering more respite care was the main avenue used to help the carer cope. In the opinion of the authors, this may be because offering more respite is the band-aid solution; it is the easiest solution to implement and is likely to provide a short-term relief to carer problems. However one can argue given the lack of services available, attempting to offer more may not be so easy. But offering more respite is much easier than coordinating a group of interventions that may not lead to quick, immediate relief of problems (but will most likely benefit the carer in the long term).

Offering short term solutions will most likely not prevent relinquishment or improve unmet need for respite care services (results of this study support this as families' still relinquished care even when more respite was offered to them). A long term strategy such as "value-adding" respite care services may be a potential strategy that can be adopted. "Value adding" would entail incorporating other interventions into the respite care process, which in turn could decrease the risk of relinquishment by increasing the coping of carers or improving the skills of the individual with a disability. For instance, McClean et al. (2007) found that implementing positive behaviour support plans in conjunction with emergency respite care was associated with reduced levels of challenging behaviour and improved quality of life for the individual with a disability. Further research could focus on incorporating empirically validated interventions, such as sleep interventions, parent training, positive behaviour supports and active support into respite care services and testing whether the inclusion of these interventions lead to longer term benefits for both families and individuals with intellectual disability, and in turn influences the occurrence of relinquishment into out-of-home respite care. 
However, this approach will not address families' and young adults' need or desire for outof-home permanent accommodation. This was a contributing factor where relinquishment was used as a strategy to achieve such placements, or where families reached a crisis and were no longer able to provide care, even with increasing amounts of respite care provided. The need for planned supports that take a longer term, life-stage view, such as transition into out-of-home permanent accommodation was expressed by families to staff and the staff interviewed also discussed this. Current levels of unmet need for out-of-home permanent accommodation act as a barrier to this.

Some limitations are present in this study which should be touched on. Research by MacDonald and Callery $(2004,2008)$ demonstrates that the type of respite care preferred by families' changes as the individual being cared for increases in age, and that increased need for respite care is associated with high support needs. Due to space limitations, a between-groups analysis conducted by the authors that analyses the effect that age and level of support needs has on a family's decision to relinquish care cannot be touched on here however the authors have every intention to publish the findings of this analysis shortly. Another limitation is that the clients sampled for this study were all from one Australian state. Future research should consider sampling across various geographical areas in order to confirm that these results can be generalised outside this population. The sample size (32 cases) reviewed is a small sample size for qualitative type research and also too small to infer associations with more certainty. Future research may want to consider sourcing a larger participant sample in order to enhance acceptability of findings in terms of qualitative methodology. Lastly, the data collected in this study came from third-party informants (staff interviews, staff case notes, professional reports etc.). Due to the timelines and sensitivity of the research, it was not possible to include family members as participants in this study. Considerations here included the recency of relinquishment occurring and the timing of the research. The researchers were aware that families may find the process of discussing relinquishment so soon after it occurring too distressing. Also, some families had made themselves un-contactable. However, future research should consider investigating relinquishment from the viewpoint of the families/carers instead of relying on third-party informants. 
In conclusion, the data and themes presented in this study provide insight into the factors that contribute to relinquishment and as such, suggest strategies that could be adopted in both policy and practice as a way of preventing relinquishment or improving respite care services. However, this study is one of the first to investigate relinquishment in the disability sector; therefore future research will need to replicate the findings of this study before adopting these findings into policy development processes. 
References

Australian Institute of Health and Welfare (2008a) Disability in Australia: Trends in prevalence, education, employment and community living. Bulletin no. 61. Canberra: Author.

Australian Institute of Health and Welfare (2008b) Disability in Australia: Intellectual disability. Bulletin no. 67. Canberra: Author.

Benedict R.E. (2006) Disparities in use of and unmet need for therapeutic and supportive services among school-age children with functional limitations: A comparison across settings. Health Service Research 41, 103-24.

Braun V. \& Clarke V. (2006) Using thematic analysis in psychology. Qualitative Research in Psychology 3, 77-101.

Bromley, J., Hare, D., Davison, K. \& Emerson, E. (2004) Mothers supporting children with autistic spectrum disorders: Social support, mental health status and satisfaction services. Autism 8, 409-423.

Burton-Smith, R., McVilly, K.R., Yazbeck, M., Parmenter, T.R. \& Tsutsui, T. (2009) Quality of life of Australian family carers: Implications for research, policy and practice. Journal of Policy and Practice in Intellectual Disabilities 6, 189-198.

Carr A. \& O'Reilly M. (1996) Service needs of carers for people with intellectual disabilities: Profiles of high-need and low-need groups. The Irish Journal of Psychology 17, 48-59.

Chan, J. (2007) Carers' perspective on respite for person with acquired brain injury. International Journal of Rehabilitation Research 30, 137-146.

Chan J. (2008) What do people with acquired brain injury think about respite care and other support services? International Journal of Rehabilitation Research 31, 3-11.

Chan J. \& Sigafoos J. (2001a) Adults with intellectual disability in long-tern respite care: A qualitative study. Journal of Intellectual and Developmental Disability 26, 339-44.

Chan J. \& Sigafoos J. (2001b) Does respite care reduce parental stress in families with developmentally disabled children? Child and Youth Care Forum 30, 253-63.

Chou Y., Tzou P., Pu C., Kroger T. \& Lee W. (2008b) Respite care as a community care service: Factors associated with the effects of family carers of adults with intellectual disability in Taiwan. Journal of Intellectual and Developmental Disability 33, 12-21. 
Clark P. \& MacArthur J. (2008) Children with physical disability: Gaps in service provision, problems joining in. Journal of Paediatrics and Child Health 44, 455-58.

Cotterill, L., Hayes, L., Flynn, M. \& Sloper, P. (1997) Reviewing respite services: Some lessons from the literature. Disability and Society 12, 775-788.

Cowley M. \& Orbell S. (1999) Towards a psychology of service use in informal care: Social and psychological variables associated with service need and uptake amongst carers of learning disabled adults. Psychology and Health 14, 217-39.

Cummins, R.A. (2001) The subjective well-being of people caring for a family member with a severe disability at home: A review. Journal of Intellectual and Developmental Disability $\mathbf{2 6}$, 83-100.

Damiani G., Rosenbaum P., Swinton M. \& Russell D. (2004) Frequency and determinants of formal respite service use among caregivers of children with cerebral palsy in Ontario. Child: Care, Health and Development 30, 77-86.

Freedman R., Griffiths D., Krauss M. \& Seltzer M. (1999) Patterns of respite use by aging mothers of adults with mental retardation. Mental Retardation 37, 93-103.

Grant, G., Ramcharan, P., McGrath, M., Nolan, M. \& Keady, J. (1998) Rewards and gratifications among family caregivers: Towards a refined model of caring and coping. Journal of Intellectual Disability Research 42, 58-71.

Hare, D.J., Pratt, C., Burton, M., Bromley, J. \& Emerson, E. (2004) The health and social care needs of family carers supporting adults with autistic spectrum disorder. Autism 8, 425-444.

Hastings, R.P. (2002) Parental stress and behaviour problems of children with developmental disability. Journal of Intellectual and Developmental Disability 27, 149-160.

MacDonald H. \& Callery P. (2004). Different meanings of respite: A study of parents, nurses and social workers caring for children with complex needs. Child: Care, Heath and Development 30, 279-288.

MacDonald H. \& Callery P. (2008) Parenting children requiring complex care: A journey through time. Child: Care, Heath and Development 34, 207-213. 
McClean B., Grey I. \& McCracken M. (2007) An evaluation of positive behavioral support for people with very severe challenging behaviors in community-based settings. Journal of Intellectual Disabilities 11, 281-301.

McConkey R. (2005) Fair shares? Supporting families caring for adult persons with intellectual disabilities. Journal of Intellectual Disability Research 49, 600-12.

McConkey R., Truesdale M. \& Conliffe C. (2004) The features of short-break residential services valued by families who have children with multiple disabilities. Journal of Social Work 4, 6175.

McNally S., Ben-Shlomo Y. \& Newman S. (1999) The effects of respite care on informal carers' well-being: A systematic review. Disability and Rehabilitation 21, 1-14.

Power A. (2008) 'It's the system working for the system': Carers' experiences of learning disability services in Ireland. Health and Social Care in the Community 17, 92-8.

Salisbury, C. (1990) Characteristics of users and nonusers of respite care. Mental Retardation 28, 291-297. 
Acknowledgements, Conflict of Interest and Source of Funding

Michelle Payne and Tashi Sinclair from RMIT University are acknowledged for their efforts during the data collection phase of this research study. 


\section{Table 1}

A summary of individual and family characteristics identified by previous research that are associated with a need for respite care

Individual Characteristics

Family Characteristics
1. Multiple and/or severe limitations of function
1. High emotional strain/distress
2. Behavioural disturbance
2. Low levels of social/informal supports
3. High levels of dependence
3. Psychological characteristics of parents
4. Low communication ability (coping styles and perceived self-efficacy)
4. Sole parenting
5. Poor health in one or both carers
6. Size of family
7. Subjective burden of care
8. Physical exhaustion
9. Financial costs/lower income

Note. Studies cited in this table are Benedict (2006); Bromley et al. (2004); Carr and O'Reilly (1996); Chan (2007, 2008); Chan and Sigafoos (2001a); Chou et al. (2008); Cohen and Warren (1985, cited in Cotterill et al. 1997); Cowley and Orbell (1999); Damiani et al. (2004); Freedman et al. (1999); McConkey (2005); and, Salisbury (1990). 


\section{Table 2}

A summary of the factors that can contribute to relinquishment

\begin{tabular}{|c|c|c|}
\hline Individual characteristics & Family characteristics & Support context \\
\hline $\begin{array}{l}\text { High support needs as a result } \\
\text { of challenging behaviours }\end{array}$ & $\begin{array}{l}\text { Carers experiencing stress, exhaustion and } \\
\text { depression }\end{array}$ & Availability of respite care \\
\hline Very high medical needs & $\begin{array}{l}\text { Single parent carers being overwhelmed by } \\
\text { the support needs of their disabled child } \\
\text { and/or other family members }\end{array}$ & $\begin{array}{l}\text { Availability of appropriate } \\
\text { supports }\end{array}$ \\
\hline $\begin{array}{l}\text { Limited communication } \\
\text { meaning that the parent(s) find } \\
\text { it difficult to develop a rapport } \\
\text { with their child }\end{array}$ & $\begin{array}{l}\text { Parental expectation that their child will move } \\
\text { into out-of-home permanent accommodation } \\
\text { when they reach young adulthood }\end{array}$ & $\begin{array}{l}\text { Experiences of social } \\
\text { isolation and a lack of } \\
\text { informal supports }\end{array}$ \\
\hline \multirow{4}{*}{$\begin{array}{l}\text { Being at or approaching young } \\
\text { adulthood age }\end{array}$} & Marital breakdown & Frustration \\
\hline & A strong desire to have a "normal" life & \\
\hline & $\begin{array}{l}\text { The acceptance of relinquishment as a } \\
\text { strategy in gaining an out-of-home placement }\end{array}$ & \\
\hline & $\begin{array}{l}\text { Carer no longer available due to ageing, ill } \\
\text { health, or death }\end{array}$ & \\
\hline
\end{tabular}


Table 3

The factors affecting access to adequate support for families

\begin{tabular}{|c|c|}
\hline Factor grouping & Elements of the factor \\
\hline $\begin{array}{l}\text { Availability of } \\
\text { respite care } \\
\text { services }\end{array}$ & $\begin{array}{l}\text { 1. Blocked beds in respite centres meaning a decreased amount of respite } \\
\text { available } \\
\text { 2. Limited out-of-home placements for children available } \\
\text { 3. Waiting for emergency funding for more respite services to be approved and at } \\
\text { times, this funding request is denied which causes a lot of frustration for the } \\
\text { family }\end{array}$ \\
\hline $\begin{array}{l}\text { Availability of } \\
\text { appropriate } \\
\text { supports }\end{array}$ & $\begin{array}{l}\text { 1. Living in a remote area leading to social isolation } \\
\text { 2. Limited out-of-home permanent accommodation options for children with the } \\
\text { Department of Child Services reporting that it does not have the resources to } \\
\text { provide this type of accommodation to children with disabilities } \\
\text { 3. The characteristics of the child/client limits the options available to the family } \\
\text { (such as shared family care) } \\
\text { 4. The supports provided do not address the actual need of the family (which is an } \\
\text { out-of-home placement) therefore any support offered is not good enough }\end{array}$ \\
\hline
\end{tabular}

